\title{
La influencia de Gran Bretaña en el pensamiento de Ramiro de Maeztu A propósito del libro de David JIMÉNEZ TORRES, «Nuestro hombre en Londres. Ramiro de Maeztu y las relaciones angloespañolas» (Marcial Pons, 2020)
}

\author{
Jorge Pérez Alonso \\ Investigador de la Cátedra Martínez Marina \\ de Historia Constitucional, Universidad de Oviedo, España \\ jpa6677@icaoviedo.es \\ https://orcid.org/0000-0001-9455-1599
}

Recibido: 21/01/2021

Aceptado: 23/06/2021

Cómo citar este artículo: PÉREZ ALONSO, Jorge (2021). La influencia de Gran Bretaña en el pensamiento de Ramiro de Maeztu. A propósito del libro de David JIMÉNEZ TORRES, «Nuestro hombre en Londres. Ramiro de Maeztu y las relaciones angloespañolas», Madrid Marcial Pons, 2020. Pasado y Memoria. Revista de Historia Contemporánea, (23), pp. 460-469, https:// doi.org/10.14198/PASADO2021.23.19

A finales de los años setenta del siglo XX, Edward Inman Fox afirmó que: «entre los intelectuales españoles de este siglo, tal vez José Ortega y Gasset y Miguel de Unamuno sean los únicos en haber superado, en intensidad de pensamiento $e$ influencia en las corrientes sociopolíticas, a Ramiro de Maeztu. Sin embargo, sigue sin aclaración, para muchos curiosos, la evolución de sus ideas...» (Maeztu: 1977: 7). Pese a esa importancia de Maeztu, se erigió en torno a su persona un auténtico muro de silencio, hasta el punto que nada menos que en 2003, la biografía prácticamente definitiva sobre Maeztu se iniciaba con estas palabras: 
"¿Ramiro de Maeztu? ¡Ah, qué tipo...! Si va a leérsele, o a estudiar su vida o sus ideas, mejor se lo piensa uno, y lo deja. Tal suele ser la primera reacción de los historiadores ante la figura de este intelectual español.» (González Cuevas: 2003, 11). Sin embargo, tan ominoso silencio no persiguió la figura de Maeztu tras su muerte, sino incluso en vida, ya que en cierta ocasión el propio afectado, al agradecer al periodista Eugenio Montes una elogiosa glosa de su obra, le aconsejó: «Pero no vuelva a hacerlo. No me cite, no me mencione. Es usted muy joven y no tiene derecho a que le cerque el silencio como a mi.» (Marrero: 1955). Con posterioridad a su trágico final, asesinado la noche del 29 de octubre de 1936 en una de las numerosas «sacas» que tuvieron lugar en el Madrid republicano de finales de octubre y principios de noviembre de 1936, la figura de Maeztu pareció no ya sumirse en la penumbra, sino incluso ser sujeto pasivo de afirmaciones realmente peculiares. Valga el siguiente párrafo con el que Andrés Trapiello inicia su referencia al personaje:

«Maeztu, en cierto modo, fue, dicho con el debido respeto, un invento del franquismo, el escritor muerto que se intentó oponer al otro muerto ilustre, que era García Lorca, en un esfuerzo desesperado de demostrar que la barbarie de la guerra se había propagado en ambas zonas por igual. Y eso que era verdad en cuanto a las vidas, no era equiparable, no podía serlo, en las obras. Si, en efecto, Lorca y Maeztu fueron los escritores asesinados más señalados de cada uno de los bandos, la comparación de sus respectivas obras literarias no puede hacerse sin incurrir en abundantes agravios comparativos». (Trapiello: 2019, 156).

Lleva razón Trapiello cuando afirma que no puede compararse a Lorca (un poeta y autor dramático) con Maeztu (un cronista político y pensador), y desde el punto estrictamente literario lleva razón, pero se olvida que con Maeztu, al igual que con Víctor Pradera (también asesinado en el conflicto) ${ }^{1}$ desaparecía uno de los pensadores que nutrían la línea ideológica de la revista Acción Española, sobre la que se sustentaría en buena parte el bando nacional ${ }^{2}$.

La evolución de los estudios acerca de la vida y obra de Ramiro de Maeztu, aun cobrando cierto vigor a principios del siglo XXI, distan mucho de alcanzar la importancia que merecería una figura tan destacada y prolífica en su

1. El caso de Víctor Pradera fue realmente trágico, pues con él se asesinó vilmente a su hijo tan sólo por el simple hecho de la filiación.

2. Sobre las bases ideológicas que nutrieron dicha publicación, es imprescindible el estudio de GONZÁLEZ CUEVAS, Pedro Carlos (1998). Acción Española, Teología política y nacionalismo autoritario en España (1913-1936). Tecnos. Esta obra está totalmente agotada y está pidiendo a gritos una reedición. 
ámbito. Orillando intentos de aproximación parciales ${ }^{3}$, el primer acercamiento biográfico a la figura de Ramiro de Maeztu data de 1955, con el estudio debido a Vicente Marrero y publicado en la editorial Rialp. Aun cuando el mismo conserva cierto interés debido a la cantidad de datos y noticias que suministra, su metodología, en vez de ayudar a la comprensión del biografiado la dificulta, al estudiar todo el periplo de Maeztu desde la óptica de su tradicionalismo final, que se proyecta en cierta medida sobre toda su vida anterior; lo cual, dada la evolución intelectual que experimentó, no es quizá el modo más apropiado de acercarse a tan interesante figura. Hubo que esperar cuarenta y cinco años para un nuevo ensayo biográfico, el debido a José Luis Villacañas (2000) que, pese a sus notables méritos (entre ellos la valentía de reivindicar a Maeztu en un ambiente no muy propicio a ello) no lograba alcanzar una comprensión total del biografiado debido a alguna que otra deficiencia y a la falta de perspectiva. No obstante, un trienio después de ver la luz la anterior biografía, apareció el ensayo debido a Pedro Carlos González Cuevas (2003) y que, a día de hoy, constituye la obra de referencia obligada e inexcusable para acercarse a Ramiro de Maeztu. González Cuevas, una reputadísima autoridad en lo que a la evolución del pensamiento conservador español se refiere, y que había dedicado un estudio indispensable a dicha materia (González Cuevas: 2000), ya se había acercado con a la figura de Maeztu vinculándola comparativamente a otros autores (González Cuevas: 2002). En su estudio monográfico sobre el vitoriano, efectuó un profundo y exhaustivo recorrido sobre su vida y obra sin incurrir en los desenfoques de los anteriores, situando a Maeztu en cada periodo y analizando sus trabajos de forma cronológica, insertándolo en las coordenadas socio-políticas e intelectuales de cada momento y explicando detalladamente la evolución de su pensamiento así como las influencias que permearon su doctrina.

Lo mismo cabe decir de su prolífica obra, que si reducida en el número de libros, es inmensa en lo referente a artículos periodísticos. En 1952, Dionisio

3. El primero tuvo con la publicación del número 33-34 (septiembre-octubre de 1952) de los Cuadernos Hispanoamericanos, significativamente intitulado Homenaje a don Ramiro de Maeztu, y donde hay varios artículos y trabajos dedicados a su persona. El segundo es la obra colectiva En torno a Ramiro de Maeztu (Fundación Sancho el Sabio, 1974), en el cual varios autores analizan diferentes aspectos de la trayectoria vital de Maeztu. Tampoco puede descartarse a José María Marco, que en su obra La libertad traicionada: siete ensayos españoles (Planeta, 1997), incluye a Maeztu como uno de los siete personales que analiza (los otros eran nada menos que Joaquín Costa, Ángel Ganivet, Enrique Prat de la Riba, Miguel de Unamuno, Manuel Azaña y José Ortega y Gasset); Marco fue, además, uno de los autores que elevó su voz para recuperar a Maeztu y denunciar el ostracismo en el que se le mantenía. 
Gamallo Fierros intentó efectuar una identificación por orden cronológico de todas las publicaciones de Maeztu. Pese a todo, las ediciones de su obra fueron ciertamente desiguales, hasta el punto que aun ya entrada la tercera década del siglo XXI, aún no existen unas obras completas del personaje $e^{4}$. En los años cincuenta se publicaron varios tomos en Editora Nacional, siendo su biógrafo Vicente Marrero el responsable de su contenido y ordenación ${ }^{5}$. Sin embargo, la sistemática utilizada por Marrero, dada la evolutiva trayectoria intelectual de Maeztu, no era quizá la más adecuada, puesto que la ordenación se efectuaba por materias, y no por etapas vitales, y, además, incluso en cada tomo se prescindía del orden cronológico, lo que en la práctica suponía en cierta medida una ausencia de perspectiva. En fecha tan tardía como 1974, gracias al impulso del entonces Director General de Cultura Popular, Ricardo de la Cierva (admirador confeso de Maeztu) se publicó el voluminoso tomo que, con el título Obra, recopilaba varios de los trabajos de Maeztu publicados en forma de libro, pero al igual que las anteriores (no en vano el responsable del mismo era Vicente Marrero, encargado de prologarla), desde la óptica de reivindicar al último Maeztu, al tradicionalista ${ }^{6}$. Esta obra marca el canto de cisne de la recopilación de obras efectuada desde la perspectiva conservadora.

La perspectiva que incidía en el Maeztu tradicionalista dio un giro de ciento ochenta grados en la segunda mitad de los años setenta, pues desde ese momento va a ponerse el foco en la etapa inicial, caracterizada por un radicalismo aparentemente socialista, si bien con un pronunciado antiestatalismo. Junto a aproximaciones al Maeztu regeneracionista debidas a Blanco Aguinaga (1978) y José Luis Abellán (1973), se intentan recuperar algunos de los textos más significativos de esta etapa inicial. Así, en 1974 se publicó en Taurus la

4. González Cuevas afirma que entre los motivos de la ausencia de estudios sobre su figura se debe a "la ausencia de una edición de obras completas; y que la mayor parte de su extensa producción permanezca todavía dispersa en las hemerotecas, lo que hace muy difícil y trabajosa su investigación»; Maeztu, op. cit., p. 11

5. Los tomos en cuestión fueron: Con el Directorio Militar, La liquidación de la monarquía parlamentaria, Norteamérica desde dentro, El sentido reverencial del dinero, Las letras y la vida en la España de entreguerras, El nuevo tradicionalismo y la revolución social, Un ideal sindicalista y Autobiografía. Ya extramuros de Editora Nacional, la editorial Rialp se publicó una antología con el significativo título Frente a la República (si bien en esta ocasión fue Gonzalo Fernández de la Mora el responsable de la selección, a la que antepuso un interesantísimo estudio preliminar), Defensa del espiritu y Los intelectuales y un epílogo para estudiantes.

6. MAEZTU, Ramiro de (1974). Significativamente, no se incluye Hacia otra España (que sí se había publicado como tomo en la misma editorial en los años cincuenta) al que sustituye por la recopilación que con el epígrafe «Autobiografía» recoge varios artículos de tal carácter; el tomo incluía, además, La crisis del humanismo, Don Quijote, don Juan y la Celestina, El sentido reverencial del dinero, Defensa de la Hispanidad y Defensa del Espíritu. 
única novela debida al vitoriano, La guerra del Transvaal y los misterios de la banca de Londres, a cargo de Edward Inman Fox, que tres años más tarde fue el responsable de una magnífica edición de algunos de los primeros artículos de Maeztu (1977) y diez años más tarde una breve antología de textos fabianos (Maeztu: 1984). En el año 1997, con motivo del centenario del desastre del 98, se rescata Hacia otra España (Maeztu: 1997), y tres años después, un conjunto de trabajos del primer Maeztu, gracias al esfuerzo de Emilio Palacios ${ }^{7}$. Desde el año 2000 se han reeditado varias de sus obras publicadas como libro, en concreto una edición de La crisis del humanismo ${ }^{8}$, tres de Defensa de la Hispanidad $^{9}$, una de $\mathrm{El}$ sentido reverencial del dinero ${ }^{10}$, una de su novela La guerra del Transvaal ${ }^{11}$ y, con motivo del centenario del inicio de la Gran Guerra, una nueva edición del libro Inglaterra en Armas ${ }^{12}$.

\section{II}

A la vista de lo anteriormente expuesto, puede comprobarse que el interés por la figura de Ramiro de Maeztu apuntó, bien a la ideología tradicionalista de sus últimos años (característica de los años cincuenta a setenta del siglo pasado) o bien a sus inicios radicales (desde mediados de los setenta hasta finales del siglo XX). Sin embargo, la etapa intermedia, los nada menos que tres lustros durante los cuales Maeztu fue corresponsal español en Londres, apenas despertaron interés, lo cual tiene difícil explicación, al haber sido tanto la presencia física en el territorio británico como la toma de contacto con la política y las líneas de pensamiento existentes en la Gran Bretaña post-victoriana las que serán determinantes en la evolución intelectual que experimentará Ramiro de Maeztu. Pero ese olvido es, además, incomprensible dado lo prolífico del autor, pues en estos años de estancia londinense elabora más de dos mil artículos con destino a los más importantes diarios españoles.

Sería inexacto decir que no existen estudios sobre la etapa inglesa de Ramiro de Maeztu. Manuel Fraga Iribarne dedicó un breve trabajo al tema ${ }^{13}$,

7. MAEZTU, Ramiro de (2000). Obra literaria olvidada, con un amplio y exhaustivo estudio preliminar de Emilio Palacios Fernández. Esta edición incluye la única obra de teatro (no estrenada nunca) El sindicato de las esmeraldas.

8. Almar, 2000.

9. La más reciente, en Almuzara, 2017.

10. Ediciones Encuentro, 2013

11. Salto de Página, 2012.

12. Crónicas de la Gran Guerra. Inglaterra en Armas y otras visitas al frente, Ergástula, 2014.

13. Lo incluyó en su recopilación de estudios El pensamiento conservador español (1984), Planeta, donde se acercaba igualmente a las figuras de Jovellanos, Balmes, Cánovas y Maura. 
pero con afán más didáctico y divulgativo que ensayístico. En el otro extremo, la aproximación de Rafael Santervás (1987) aborda casi agotadoramente el tema, si bien con el inconveniente de tratarse de una tesis doctoral que no fue objeto de publicación y que, por tanto, tuvo una difusión muy limitada reducida a círculos académicos. Desde el trabajo de Santervás, hubo que esperar casi tres décadas para que hiciese su aparición un nuevo trabajo dedicado a la etapa inglesa de Ramiro de Maeztu, y éste no fue otro que el publicado en inglés por David Jiménez Torres (2016), obra cuya edición revisada y ampliada acaba de aparecer traducida al español, si bien con un título ciertamente evocador de Graham Greene. El autor ya había ofrecido una especie de anticipo de la obra en un breve artículo aparecido hace ya cinco años, cuyas tesis amplía y desarrolla en el presente estudio (2015: 49-74).

El libro en el que Jiménez Torres sintetiza la etapa inglesa de Ramiro de Maeztu no es excesivamente amplio (doscientas veinte páginas si se incluyen índices y bibliografía) y se estructura internamente en cuatro partes bien diferenciadas pues, además, coinciden cada una de ellas con uno de los cuatro capítulos en que se divide la obra. El primero de ellos, titulado Genealogía de la anglofilia española, profundiza sobre el particular, efectuando una aproximación general al tema para, ulteriormente, centrarlo en Ramiro de Maeztu, si bien sobre este particular se extiende en los dos capítulos siguientes. No era infrecuente que españoles inicialmente adscritos a unas tesis revolucionarias o radicales templasen su pensamiento al entrar en contacto con el mundo anglosajón, para lo cual basta acudir a los ejemplos que nos han ofrecido Blanco White, Martínez de la Rosa, el conde de Toreno ${ }^{14}$, o los miembros de la Institución Libre de Enseñanza, a los que expresamente se refiere Jiménez Torres. Es sumamente interesante el tratamiento que se efectúa del triple factor determinante de la imagen o perspectiva que los autores españoles tenían del mundo anglosajón: político, educativo y racial. En el caso de Maeztu, influye también la mezcla cultural existente en el tronco familiar ${ }^{15}$ que influyó notablemente en su visión inicial del mundo anglosajón. No obstante, ya durante su etapa noventayochista, Maeztu ya manifestaba una característica que en cierto modo le orientaba hacia el modelo inglés:

14. Nadie ha estudiado mejor el influjo del pensamiento inglés en el primer liberalismo español que VARELA SUANZES-CARPEGNA (1995). Una versión muy revisada de dicho trabajo se incorporó como capítulo sexto de su libro La monarquía doceañista (1810-1837), Marcial Pons, 2013.

15. Ramiro de Maeztu era hijo de padre cubano y madre francesa de padres ingleses. Por cierto, Maeztu era hijo natural, algo que la biografía de Marrero, dada la época en que fue escrita, obviamente no reflejó. 
la defensa de la industrialización peninsular. En esto difería notablemente de sus colegas de generación. Así, por ejemplo, si tomamos como ejemplo a otro titán del 98, José Martínez Ruíz «Azorín», veremos que salvo en el radicalismo inicial, ni en el estilo ni en la temática existe semejanza entre el valenciano y el vitoriano. La visión idílica azoriniana de la Castilla eterna, con sus pueblecitos perdidos y solitarios donde sus habitantes gozaban de una vida idílica y tranquila que apenas había sufrido alteración desde los tiempos de Cervantes ${ }^{16}$, en nada se parece a la visión pesimista de Maeztu, que en su lugar veía la decadencia de España en el atraso castellano, mientras entonaba elogioso las glorias del Bilbao industrial y abogaba por una colonización fabril de la meseta castellana.

Sin duda alguna, lo más interesante del libro de David Jiménez Torres son el segundo y el tercer capitulo, dedicados respectivamente a la imagen que Maeztu transmite de Gran Bretaña así como la influencia o impacto que el sistema y el pensamiento existente en dicho país tuvo sobre el vitoriano. Para ello, el autor se sumerge en esa pléyade de artículos que, como corresponsal español en Londres, Maeztu remitía a los periódicos españoles, de entre los cuales destacan La Correspondencia de España, Nuevo Mundo y El Heraldo de Madrid; dicho sea de paso, es francamente incomprensible que a estas alturas, pese al enorme volumen y calidad de los trabajos de Maeztu como corresponsal español en Gran Bretaña, tan sólo exista en castellano un ínfimo ejemplo de los mismos que se remonta, además, a mediados de los años ochenta del siglo $\mathrm{XX}^{17}$. Jiménez Torres no sólo ofrece al lector un panorama del sistema y la sociedad que Maeztu se encontró al poner pie en suelo inglés, sino que explicita, además, que esa admiración de Maeztu por el mundo anglosajón tenía sus altibajos. Y buena prueba de ello es la obra de teatro (lamentablemente no estrenada) El sindicato de las esmeraldas, donde en cierta medida prolonga la negativa visión del mundo y de la sociedad británica de la que había hecho gala años antes en el folletín La guerra del Transvaal. Pero tan importante como la imagen que Maeztu transmitía de Gran Bretaña y del devenir político y social de la por entonces primera potencia mundial, es no menos importante la influencia que determinadas corrientes de pensamiento inglés tuvieron sobre el corresponsal español, y que iban a determinar, a la postre, el giro ideológico que culminaría

16. Visión que tiene su quintaesencia en el libro Castilla y que, con ciertos matices, compartía Antonio Machado en sus poemas. Esa contemplación tan favorable fue expresamente impugnada en la obra de un ilustre castellano, Miguel Delibes, pudiendo servir como ejemplo su recopilación antológica Castilla, lo castellano y los castellanos, Planeta, 1979.

17. La citada recopilación de textos fabianos debida a Inman Fox alcanza tan sólo ciento doce páginas, lo cual es hartamente significativo. 
ya en la década de los años veinte, donde Maeztu apoyaría la dictadura de Primo de Rivera ${ }^{18}$ y sostendría un pensamiento tradicional que explicitaría, en plena República, en sus artículos publicados en Acción Española. A esa influencia dedica Jiménez Torres el tercer capítulo del libro, que no en vano lleva por título Lo que Maeztu aprendió en Inglaterra, etapa decisiva por cuanto, como se manifiesta abiertamente en la obra: «fue precisamente en Inglaterra donde Maeztu comenzó su gran giro conservador», inicio del que sería máxima expresion el libro Authority, Liberty and function in the light of the war, publicado en lengua inglesa en 1916 y que vio la luz en España tres años más tarde con el título La crisis del humanismo. Es destacable el análisis que se efectúa del contacto que Maeztu tuvo con el pensamiento fabiano o socialdemócrata y autores como George Bernard Shaw y Herbert George Wells ${ }^{19}$, así como la influencia que Hilaire Belloc, Gilbert Keith Chesterton y T. E. Hulme tienen en la evolución del pensamiento de Ramiro de Maeztu hacia posturas conservadoras, a lo que se dedica gran parte del tercer capítulo. El cuarto y último nos sitúa ya a Ramiro de Maeztu de vuelta en España (regresó de Londres en 1919, justo al finalizar la Gran Guerra) y desarrolla las consecuencias que la estancia británica de Maeztu proyectó sobre su pensamiento ulterior. En este punto, son particularmente interesantes las reflexiones en las que se rastrean los orígenes de la teoría de la Hispanidad no, como es habitual, a finales de los años veinte con motivo del contacto de Maeztu con Hispanoamérica durante su etapa como embajador español en Argentina, sino en el ecuador de su etapa londinense, en 1911. El libro demuestra cómo, pese a su regreso a España, Maeztu no perdió contacto con el pensamiento inglés, si bien fugazmente orientó su atención hacia los Estados Unidos, a los que dedicó igualmente unos interesantes artículos.

Cuando en 1899 Maeztu publicó su primer libro, Hacia otra España (en realidad, una simple recopilación de algunos de los artículos que habían aparecido en diversos periódicos) incluyó unos breves párrafos a modo de introducción, en los cuales afirmaba: «Esta anarquía creo no impedirá que se destaquen los únicos sentimientos que palpitan en todos mis artículos [...] mueve mi pluma el dolor de que mi patria sea chica y esté muerta, y el furioso anhelo de que viva y se agrande, haciendo más intensa la actividad en las faenas materiales y en las

18. Maeztu no fue, ciertamente, el único en apoyar a Miguel Primo de Rivera, pues desde José Ortega y Gassett hasta Pablo Iglesias Posse, todos recibieron con cierto alivio y esperanza a la dictadura. Maeztu, según sus propias palabras, no podía alabar los logros de la dictadura y negar a quien era responsable de los mismos.

19. Maeztu fue el encargado de traducir al español la famosa novela de Wells, La guerra de los mundos. 
labores de inteligencia.» (Maeztu: 1997). Tal afirmación puede aplicarse no sólo a los trabajos recopilados en dicho libro, sino a toda la obra de Maeztu, siempre orientada a lograr que su patria fuese más grande. Lo único que modificó fueron los remedios que ofrecía para ello.

\section{III}

Tan sólo el espíritu inquisitorial que, en todos los ámbitos, se encuentra presente a diestra y a siniestra, explica el olvido doloso y doloroso con que, por razones exclusivamente políticas, se trata a algunos de nuestros más señeros autores $^{20}$. Ramiro de Maeztu ha sido una de las grandes figuras del periodismo político español, y atesora una producción ingente que debiera ser objeto de cuidado, estudio y difusión. Sin embargo, quien desee sumergirse en la obra de una de las personalidades más destacadas y relevantes de la edad de plata de la cultura española, deberá acudir a recopilaciones que, amén que algunas de ellas no se reeditan desde hace setenta años y, por tanto, sólo están disponibles (y de forma muy limitada) en librerías especializadas en la venta de libros descatalogados, no son las más adecuadas para el estudio y comprensión del autor. Bien es cierto que la impagable labor de la Biblioteca Nacional a la hora de digitalizar los principales diarios facilita al publico que, a través de la Hemeroteca Digital ${ }^{21}$ y mediante las herramientas de búsqueda, puedan consultarse los numerosos artículos que Ramiro de Maeztu enviaba desde el país de la bruma. No obstante, igual que es de agradecer que el pasado año vieran por fin la luz las Obras completas de otro gran periodista, Manuel Chaves Nogales, sería igualmente deseable que se asumiera editorialmente la tarea de efectuar una edición crítica y lo más completa posible de una de las personalidades más interesantes e intelectualmente brillantes de la primera mitad del siglo XX. Ojalá este deseo no caiga en saco roto.

\section{Bibliografía}

ABELLÁN, José Luis (1973). Sociología del 98. Barcelona: Península.

BLANCO AGUINAGA, Carlos (1978). Juventud del 98. Barcelona: Crítica.

CHAVES NOGALES, Manuel (2020). Obras completas. Libros del Asteroide.

20. Tal ha acontecido, por ejemplo, con César González Ruano, otro de los grandes nombres de referencia en el periodismo español. La labor de recuperación de su obra que había llevado a cabo la Fundación Mapfre, con la publicación de cuatro gruesos tomos recopilatorios de sus artículos y necrológicas, en cuidadísimas ediciones a cargo de Miguel Pardeza Michardo, se ha detenido de forma incomprensible, más por razones políticas que culturales.

21. http://hemerotecadigital.bne.es/index.vm 
FRAGA IRIBARNE, Manuel (1984). El pensamiento conservador español. Barcelona: Planeta.

GAMAllO FIERROS, Dionisio (1952). Hacia un Maeztu total. Cuadernos Hispanoamericanos, 279-496.

GONZÁLEZ CUEVAS, Pedro Carlos (1998). Acción Española, Teología política y nacionalismo autoritario en España (1913-1936). Madrid: Tecnos.

GONZÁLEZ CUEVAS, Pedro Carlos (2000). Historia de las derechas españolas, de la Ilustración a nuestros días. Madrid, Biblioteca Nueva.

GONZÁLEZ CUEVAS, Pedro Carlos (2002). La tradición bloqueada. Tres ideas políticas en España: el primer Ramiro de Maeztu, Charles Maurras y Carl Schmitt. Madrid, Biblioteca Nueva.

GONZÁLEZ CUEVAS, Pedro Carlos (2003). Maeztu, biografía de un nacionalista español. Madrid: Marcial Pons.

JIMÉNEZ TORRES, David (2015). Las múltiples caras de un intelectual: Ramiro de Maeztu ante la Gran Guerra. Historia y Política, 33, 49-74.

JIMÉNEZ TORRES, David (2016). Ramiro de Maeztu and England: Imaginaries, realities and repercussions of a cultural encounter. Woodbridge: Tamesis.

JIMÉNEZ TORRES, David (2020). Nuestro hombre en Londres. Ramiro de Maeztu y las relaciones angloespañolas. Madrid: Marcial Pons.

MAEZTU, Ramiro de (1977). Artículos desconocidos, 1897-1904. Madrid: Castalia.

MAEZTU, Ramiro de (1984). Liberalismo y Socialismo. Madrid: Centro de Estudios Constitucionales.

MAEZTU, Ramiro de (1997). Hacia otra España. Madrid: Biblioteca Nueva.

MAEZTU, Ramiro de (2000). Obra literaria olvidada. Madrid: Biblioteca Nueva. Prólogo de Emilio Palacios.

MARRERO, Vicente (1955). Maeztu. Madrid: Rialp.

PALACIOS FERNÁNDEZ, Emilio (1982). Ramiro de Maeztu: La labor literaria de un periodista. Diputación de Vitoria.

SANTERVÁS, Rafael (1987). La etapa inglesa de Ramiro de Maeztu. 3 vols. Universidad Complutense de Madrid.

TRAPIELLO, Andrés (2019). Las armas y las letras. Literatura y guerra civil (19361939). Austral.

VAL, Venancio del (coord.) (1974). En torno a Ramiro de Maeztu. Fundación Sancho el Sabio.

VARELA SUANZES-CARPEGNA, Joaquín (1995). El pensamiento constitucional en el exilio: el abandono del modelo doceañista (1823-1833). Revista de Estudios Políticos (nueva época) 88, 63-90.

VILLACAÑAS BERLANGA, José Luis (2000). Ramiro de Maeztu y el ideal de la burguesía en España. Madrid: Espasa. 